\title{
Obesity determinants among Malaysian 12-year old school adolescents: findings from the HAT study
}

\author{
Aryati Ahmad ${ }^{1,2^{*}}$, Nurzaime Zulaily ${ }^{1}$, Mohd Razif Shahril ${ }^{3}$, Sharifah Wajihah Wafa ${ }^{1}$, Rahmah Mohd Amin ${ }^{4}$, \\ Carmen Piernas $^{2}$ and Amran Ahmed ${ }^{5}$
}

\begin{abstract}
Background: Childhood obesity has been associated with increased odds of adult obesity and co-morbidities in later life. Finding the key determinants may help in designing the most appropriate and effective interventions to prevent obesity. This study aimed to identify the determinants of obesity among school adolescents in a sub-urban state of Malaysia.

Methods: This cross-sectional study involved 1,404 school adolescents aged 12 years (46\% boys and 54\% girls). Socio-demographic, dietary and physical activity data were collected using questionnaires whilst body weight and height were measured and body mass index was classified based on WHO BMI-for-age Z-scores cut-off.

Results: A multivariable linear regression model showed that BMI z-score was positively associated with parents' BMI $(P<0.001)$, birth weight $(P=0.003)$, and serving size of milk and dairy products $(P=0.036)$ whilst inversely associated with household size $(P=0.022)$. Overall, $13.1 \%$ of the variances in BMI Z-scores were explained by parents' BMI, birth weight, servings of milk and dairy products and household size.

Conclusion: This study found important determinants of body weight status among adolescents mainly associated with family and home environmental factor. This evidence could help to form the effective and tailored strategies at the earliest stage to prevent obesity in this population.
\end{abstract}

Keywords: Obesity, Adolescents, Childhood obesity, Risk factors

\section{Introduction}

Coupled with the increasing burden of adult obesity, obesity rates among schoolchildren and adolescents are skyrocketing worldwide $[1,2]$. This problem has become epidemic in most developed countries, but it is now emerging in many developing countries. The prevalence had dramatically increased from 35 million in 2010 by 44 times in 2016 in which 1.9 billion adults worldwide aged

\footnotetext{
*Correspondence: aryatiahmad@unisza.edu.my

1 Faculty of Health Sciences, Universiti Sultan Zainal Abidin, 21300 Kuala Nerus, Terengganu, Malaysia

Full list of author information is available at the end of the article
}

more than 18 years were classified as overweight and of that, 650 million were obese [3]. Notwithstanding, 38 million children under the age of 5 were overweight or obese whilst over 340 million children and adolescents aged 5-19 were categorized as overweight or obese in 2016 [3].

Previous evidence from developing countries reported the highest prevalence of childhood obesity in the Middle East (89.6\%) and Eastern Europe (48.4\%) in which Asian countries showed a low prevalence of childhood obesity $[4,5]$. Nevertheless, the prevalence of childhood and adolescence obesity in Malaysia has increased exponentially from $5.4 \%$ in 2006 to $6.1 \%$ in 2011 and almost doubled to 
$11.9 \%$ in 2015 and $14.8 \%$ in 2019 [6-9]. Another national and state-level studies published in 2017 reported an approximately $27-30 \%$ of primary school-aged children were either overweight or obese $[5,10]$.

The epidemic of adolescence obesity has triggered an alarm among the healthcare authorities. Like underweight, obesity is known to be one of the main contributors to higher morbidity and mortality due to later co-morbidities and complications [11, 12]. In addition to poor quality of life and reduction in productivity, the wide spectrum of obesity-related co-morbidities during teenage years and adulthood has caused a significant financial implication to the country.

Although many studies have been conducted to investigate the causes of obesity, the available findings among children are still inconclusive [13]. The evidence from the developed countries showed that environmental factors, lifestyle preferences including increased portion size and reduced physical activity play the pivotal roles in obesity [14]. In addition, sociodemographic determinants such as perinatal factors and parental characteristics that lead to obesogenic environment are important risks factors of overweight and obesity among children and adolescents [15]. Nonetheless, the evidence from developing countries, mainly in sub-urban areas, is relatively insufficient $[16,17]$. These evidence are incredibly important to the national health policymakers to plan for appropriate health promotion and intervention programs to prevent and treat obesity, respectively. Therefore, this study was conducted to determine the actual determinants of obesity among school adolescents in a sub-urban state of Malaysia.

\section{Methodology}

\section{Study design and participants}

This cross-sectional study was conducted as a part of the Health of the Adolescents in Terengganu study (HATs) from November 2014 to June 2015. A total population of 9,624 of 12-year-old adolescents from 136 public primary schools located in Terengganu were purposively enrolled in HATs. Each school was identified as rural or urban based on the Terengganu State Education Department (JPNT) classification. Out of 9,624 questionnaires distributed to school adolescents, $36.3 \%$ participants returned completed questionnaire $(\mathrm{n}=3,498)$. After screening for valid data and matching with the anthropometric measurement, only 1,404 participants were included in the final analysis (i.e. $14.6 \%$ of the total eligible population). In total, $40.1 \%$ of the returned questionnaire were included in the analyses whilst the remaining $59.9 \%$ of the questionnaire were excluded due to incomplete returned questionnaires or invalid data during analysis. Figure 1 shows the flow diagram of participant's inclusion at each stage. There were significant differences in distributions of adolescents in term of gender, districts, and school locations but no difference in BAZ between the included and excluded adolescents.

\section{Data collection}

Data collection involved two phases. In the first phase, anthropometric and physical fitness data were obtained from the first school term of 2015 National Physical Fitness Standard (SEGAK) assessment. The bi-annual SEGAK program (i.e. conducted in March and August) was initiated by the Malaysian Ministry of Education (MOE) in 2005 and was fully implemented nationwide starting from 2008 school session. This mandatory assessment involved all students starting from the aged of 10 until 17 years old and was conducted by physical/ health education (PE) teachers in schools. Five main components were assessed in each student including measurement of BMI, and four physical fitness components (i.e. step-ups, push-ups, partial curl-ups and a sit and reach test). For the purpose of HATs data collection procedure,

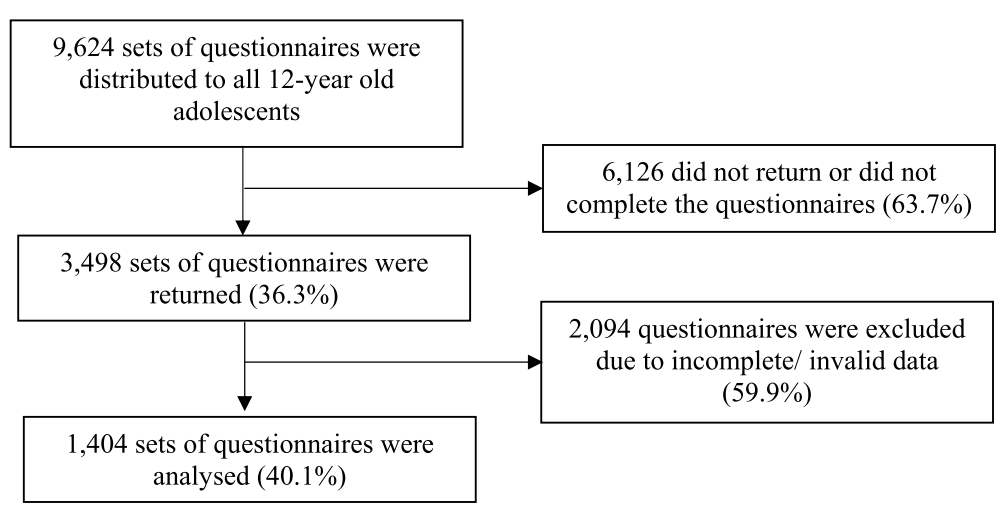

Fig. 1 Flow diagram of participant's inclusion 
complete data of each student were uploaded according to school by PE teachers into a web portal named Health Monitoring System (HEMS).

The second phase of data collection involved a selfreported questionnaire consisted of components on socio-demographic determinants, dietary intake (Food Frequency Questionnaire, FFQ) and physical activity level (Physical Activity Questionnaire for Older Children, cPAQ). The FFQ was made up of sixteen food groups with a total of 187 food items. FFQ was adapted from the Malaysia Adult Nutrition Study (MANS) and was added with regional food items related to children and adolescents. The physical activity level of children was assessed using Children Physical Activity Questionnaire (cPAQ) [18]. The questionnaire was modified, adapted, translated and validated among Malaysian schoolchildren with good internal consistency and acceptable validity [19]. Parents were asked to complete the sociodemographic questionnaire while the participants completed the FFQ and $\mathrm{CPAQ}$ guided by PE teachers at school. The sociodemographic questionnaire aimed to gather information on the biological factors (i.e. birth weight, breastfeeding practice, current parent's weight and height), socioeconomic status (i.e. household income, household size and maternal working status), and parental education status and family structure (i.e. parental age and marital status). Parental BMI was calculated by dividing body weight (in kilogram) with height in (in metre square). BMI $\left(\mathrm{kg} / \mathrm{m}^{2}\right)$ was categorized using the World Health Organization (WHO) definitions [20]: BMI of $18.5-24.9 \mathrm{~kg} / \mathrm{m}^{2}$ used as the reference (normal BMI), $25-29.9 \mathrm{~kg} / \mathrm{m}^{2}$ was used to define overweight while $\geq 30 \mathrm{~kg} / \mathrm{m}^{2}$ was used for definition of obesity.

This study obtained ethical approval from the Universiti Sultan Zainal Abidin Human Research Ethics Committee (UHREC) (UniSZA.N/1/628- 1 Jld.2 (11)). Permission to conduct the study was obtained from the Malaysian Ministry of Education and the Terengganu State Education Department. Informed written parental consent was obtained prior to any data collection.

\section{Anthropometric measurements}

Weight and height of participants were measured by trained PE teachers in each respective school using standardised protocol and uploaded into a specifically developed database in the HEMS web portal [21]. Prior to SEGAK assessments, PE teachers were provided with intensive training on appropriate anthropometric measurement techniques and reference materials. The assessments conducted by the PE teachers were proven reliable [22]. Body weight was measured to the nearest $0.1 \mathrm{~kg}$ using calibrated analogue health scales. Body height was measured to the nearest $0.1 \mathrm{~cm}$ using a wall-mounted stadiometer without shoes. All measurements were conducted in light sport attires during mornings or early afternoon. BMI-for-age z-score of each participants was calculated using WHO AnthroPlus software by entering data on date of measurement, date of birth, weight, height and gender [23]. WHO age- and sex-specific BMI z-score cut-off for 5-19 years old reference was used to define BMI categories of each participant. Based on the WHO reference, each participant was classified into "Thin" (BMI z-score < -1 SD), "Normal" (BMI z-score between -1 to $+1 \mathrm{SD}$ ), "Overweight" (BMI z-score $>+1$ $\mathrm{SD})$, and "Obese" (BMI z-score > +2 SD).

\section{Statistical analysis}

Data were analysed using IBM SPSS Statistics for Windows, Version 22.0 software (IBM Corporation, Armonk, New York, USA). A two-sided $\mathrm{P}<0.05$ was considered as statistically significant. Distributions of categorical variables are presented as frequency statistics (percentages). Continuous variables are presented as mean \pm standard deviation (SD). To examine variation in continuous variables between two groups, an independent sample t-test was performed. One-way analysis of variance (ANOVA) was used to assess associations between continuous and categorical data whilst associations between categorical variables were tested using Pearson's chi-square tests. Multiple linear regression analysis was used to examine the association between selected independent variables on the BMI-for-age $\mathrm{z}$-score (BAZ) of the adolescents. Variables associated with BMI-for-age $\mathrm{z}$-score at $P<0.25$ in univariate analyses were included in the multivariate analysis where $P<0.05$ were considered significant. Significant covariates including gender, districts and school locations were also adjusted in the final model. Any missing data were treated accordingly by SPSS.

\section{Results}

A total of 1,404 school adolescents were included in this study. Of all, $46.3 \%$ were boys and $53.7 \%$ were girls of which the majority of them (67.7\%) were from urban areas. While the mean BMI of all participants was $19.1 \pm 4.5 \mathrm{~kg} / \mathrm{m}^{2}$, boys had a slightly lower mean BMI than girls $\left(18.9 \pm 4.4 \mathrm{~kg} / \mathrm{m}^{2}\right.$ vs $19.2 \pm 4.6 \mathrm{~kg} / \mathrm{m}^{2}$ ) (Table 1$)$. However, there were no significant differences in mean BMI and BAZ between gender and school locations.

Overall, the majority of participants (59.2\%) were categorised as normal according to BAZ whilst $15.2 \%$ and $17.4 \%$ were in the obese and overweight category, respectively (Table 1). There were $16.3 \%$ and $18.5 \%$ of boys with obesity and overweight, meanwhile $14.2 \%$ and $16.4 \%$ of girls were categorised as obese and overweight. In term of school locations, $15.5 \%$ and $18.4 \%$ of urban adolescents were categorised as obese and overweight whilst, 
Table 1 Anthropometric and socio-demographic characteristics by BMI categories of school adolescents

\begin{tabular}{|c|c|c|c|c|c|}
\hline Socio-demographic characteristics & $\begin{array}{l}\text { Thin } \\
(n=116)\end{array}$ & $\begin{array}{l}\text { Normal } \\
(n=831)\end{array}$ & $\begin{array}{l}\text { Overweight } \\
(n=244)\end{array}$ & $\begin{array}{l}\text { Obese } \\
(n=213)\end{array}$ & $\begin{array}{l}P \text {-value } \\
\text { (x) }\end{array}$ \\
\hline Weight & $26.6 \pm 3.2$ & $34.9 \pm 5.5$ & $47.1 \pm 6.2$ & $59.9 \pm 10.7$ & $<0.001^{b}$ \\
\hline Height & $141 \pm 7.7$ & $143.2 \pm 7.6$ & $146.6 \pm 8.5$ & $147.3 \pm 12.6$ & \\
\hline BMI & $13.4 \pm 0.8$ & $16.9 \pm 1.6$ & $21.8 \pm 1.1$ & $27.3 \pm 3.2$ & \\
\hline BAZ & $-2.8 \pm 0.7$ & $-0.4 \pm 08$ & $1.5 \pm 0.3$ & $2.6 \pm 0.5$ & \\
\hline \multicolumn{6}{|l|}{ Gender } \\
\hline Boys & $50(7.7)$ & $374(57.5)$ & $120(18.5)$ & $106(16.3)$ & \multirow{2}{*}{$\begin{array}{l}0.411 \\
(2.9)\end{array}$} \\
\hline Girls & $66(8.8)$ & $457(60.6)$ & $124(16.4)$ & $107(14.2)$ & \\
\hline \multicolumn{6}{|l|}{ Demographic factors } \\
\hline \multicolumn{6}{|l|}{ Locality } \\
\hline Rural & $45(9.9)$ & $273(60.3)$ & $69(15.2)$ & $66(14.6)$ & 0.228 \\
\hline Urban & $71(7.5)$ & $558(58.7)$ & $175(18.4)$ & $147(15.5)$ & $(4.3)$ \\
\hline \multicolumn{6}{|l|}{ Biological factors } \\
\hline \multicolumn{6}{|l|}{ Ethnicity } \\
\hline Malay & $110(8.3)$ & $781(59.3)$ & $225(17.1)$ & $202(15.3)$ & 0.634 \\
\hline Non-Malay & $6(7.0)$ & $50(58.1)$ & $19(22.1)$ & $11(12.8)$ & $(1.7)$ \\
\hline \multicolumn{6}{|l|}{ Birth weight } \\
\hline Low birth weight (<2.5 kg) & $21(12.3)$ & $101(59.1)$ & $29(17.0)$ & $20(11.7)$ & 0.280 \\
\hline Normal $(2.5-4.2 \mathrm{~kg})$ & $84(8.3)$ & $593(58.5)$ & $186(18.3)$ & $151(14.9)$ & (3.8) \\
\hline \multicolumn{6}{|l|}{ Breastfeeding history } \\
\hline Yes & $111(8.6)$ & $767(59.5)$ & $224(17.4)$ & $188(14.6)$ & 0.654 \\
\hline No & $5(6.8)$ & $40(54.8)$ & $14(19.2)$ & $14(19.2)$ & $(1.6)$ \\
\hline \multicolumn{6}{|l|}{ Gestational DM } \\
\hline Yes & $5(4.5)$ & $63(56.8)$ & $23(20.7)$ & $20(18.0)$ & 0.312 \\
\hline No & $107(8.8)$ & $716(58.8)$ & $215(17.7)$ & $179(14.7)$ & (3.6) \\
\hline \multicolumn{6}{|l|}{ Mother's perceived BMI (current) } \\
\hline Underweight & $6(14.6)$ & $26(63.4)$ & $4(9.8)$ & $5(12.2)$ & $<0.001$ \\
\hline Normal & $36(10.2)$ & $229(65.1)$ & $54(15.3)$ & $33(9.4)$ & $(33.3)$ \\
\hline Overweight & $24(7.0)$ & $193(56.1)$ & $67(19.5)$ & $60(17.4)$ & \\
\hline Obese & $5(3.3)$ & $80(52.6)$ & $31(20.4)$ & $36(23.7)$ & \\
\hline \multicolumn{6}{|l|}{ Father's perceived BMI (current) } \\
\hline Underweight & $4(21.1)$ & $12(63.2)$ & $2(10.5)$ & $1(5.3)$ & $<0.001$ \\
\hline Normal & $32(10.9)$ & $205(69.7)$ & $39(13.3)$ & $18(6.1)$ & $(55.3)$ \\
\hline Overweight & $20(6.8)$ & $154(52.4)$ & $59(20.1)$ & $61(20.7)$ & \\
\hline Obese & $7(4.6)$ & $77(51.0)$ & $30(19.9)$ & $37(24.5)$ & \\
\hline \multicolumn{6}{|l|}{ Economic status } \\
\hline Household size & $6.52 \pm 2.0$ & $6.52 \pm 2.06$ & $6.27 \pm 2.12$ & $6.06 \pm 1.69$ & $0.016^{c}$ \\
\hline Household income (RM) & $2622.8 \pm 3300.8$ & $2686 \pm 3042.7$ & $3280 \pm 3426.9$ & $4380 \pm 3467^{*}$ & $<0.001$ \\
\hline \multicolumn{6}{|l|}{ Income level } \\
\hline Low (<RM 2300) & $60(8.6)$ & $413(62.1)$ & $118(17.1)$ & $69(12.2)$ & $<0.001$ \\
\hline Middle (RM 2300-5599) & $17(8.2)$ & $124(57.5)$ & $33(14.6)$ & $40(19.7)$ & $(31.3)$ \\
\hline High (> RM 5600) & $13(6.7)$ & $88(46.7)$ & $42(22.1)$ & $47(24.6)$ & \\
\hline \multicolumn{6}{|l|}{ Mother's current working status } \\
\hline Working & $44(8.6)$ & $272(52.9)$ & $105(20.4)$ & $93(18.1)$ & 0.001 \\
\hline Not working & $67(8.9)$ & $474(62.9)$ & $121(62.9)$ & $92(12.2)$ & $(15.7)$ \\
\hline \multicolumn{6}{|l|}{ Education status } \\
\hline \multicolumn{6}{|l|}{ Mother's educational level } \\
\hline Primary education & $7(5.4)$ & $78(60.0)$ & $27(20.8)$ & $18(13.8)$ & 0.021 \\
\hline Secondary education & $89(9.1)$ & $599(61.0)$ & $161(16.4)$ & $133(13.5)$ & $(14.9)$ \\
\hline Tertiary education & $19(8.2)$ & $116(50.0)$ & $51(22.0)$ & $46(19.8)$ & \\
\hline
\end{tabular}


Table 1 (continued)

\begin{tabular}{|c|c|c|c|c|c|}
\hline Socio-demographic characteristics & $\begin{array}{l}\text { Thin } \\
(n=116)\end{array}$ & $\begin{array}{l}\text { Normal } \\
(n=831)\end{array}$ & $\begin{array}{l}\text { Overweight } \\
(n=244)\end{array}$ & $\begin{array}{l}\text { Obese } \\
(n=213)\end{array}$ & $\begin{array}{l}P \text {-value }{ }^{a} \\
(x)\end{array}$ \\
\hline \multicolumn{6}{|l|}{ Father's educational level } \\
\hline Primary education & $13(7.9)$ & $108(65.9)$ & $26(15.9)$ & $17(10.4)$ & 0.062 \\
\hline Secondary education & $70(8.2)$ & $518(60.8)$ & $140(16.4)$ & $124(14.6)$ & $(12.0)$ \\
\hline Tertiary education & $18(7.6)$ & $122(51.7)$ & $52(22.0)$ & $44(18.6)$ & \\
\hline \multicolumn{6}{|l|}{ Family structure } \\
\hline Mother's age (years) & $42.08 \pm 5.45$ & $42.63 \pm 6.04$ & $43.09 \pm 5.59$ & $42.99 \pm 6.09$ & $0.416^{c}$ \\
\hline Father's age (years) & $47.21 \pm 6.68$ & $47.15 \pm 7.2$ & $47.99 \pm 7.54$ & $47.73 \pm 7.45$ & $0.428^{c}$ \\
\hline \multicolumn{6}{|l|}{ Mother's marital status } \\
\hline Married & $105(8.3)$ & $754(59.6)$ & $218(17.2)$ & $188(14.9)$ & 0.166 \\
\hline Divorced/Single parent & $11(11.6)$ & 47 (49.5) & $23(24.2)$ & $14(14.7)$ & $(5.1)$ \\
\hline
\end{tabular}

$14.6 \%$ and $15.2 \%$ of rural adolescents were with obesity and overweight.

Data on the sociodemographic status and BMI categories are shown in Table 1. No significant associations were found between BMI categories and locality, ethnicity, birth weight, breastfeeding history and history of gestational diabetes mellitus (GDM). In contrast, there were significant differences between BMI categories and mothers' $(P<0,001 ; \lambda=33.3)$ and fathers' BMI $(P<0.001$; $\lambda=55.3$ ). With regards to their economic status, household size, household income level, mother's working status and educational level were significantly associated with BMI categories of the school adolescents. No significant differences were found between the father's educational level, the age of parents and mother's marital status and BMI category. In contrast, there were significant associations between BMI categories and energy density, carotenes, vitamin $\mathrm{C}$, and fruits and no association with other variables (Table 1 ).

All variables were tested using univariate analysis to determine their association with BMI categories. Birth weight, parents' BMI, household income, household size, parents' age, energy density from foods and beverage, calcium, carotenes, vegetables, fish, legumes and milk and dairy products were found to be associated with BMI categories (Table 2). Multivariable analysis was then conducted to examine independent predictors of body weight status of the school adolescents (Table 2). The final model showed that the mother's BMI, father's BMI, birth weight, household size and dairy products intake were the independent determinants of BMI z-score of the school adolescents. One unit higher in self-reported BMI of mother and father may increase their adolescents BMI by 0.07 unit (adjusted $\beta=0.07,95 \% \mathrm{CI}=0.04,0.1, P$ $<0.001$ ) and 0.07 (adjusted $\beta=0.0795 \% \mathrm{CI}=0.04,0.10$, $P<0.001)$, respectively. There were also significant linear relationships between birth weight and BMI z-score. Those who are $1.0 \mathrm{~kg}$ heavier at birth, may have 0.36 unit higher in BMI z-score (adjusted $\beta=0.36,95 \% \mathrm{CI}=0.12$, $0.59, P=0.003)$. Interestingly, a significant linear relationship was also found between intake of milk and milk product and BMI z-score. An increase in one serving size intake of milk and milk products will increase BMI z-score by 0.19 unit (adjusted $\beta=0.19,95 \% \mathrm{CI}=0.01$,

Table 2 Factors associated with BMI z-score of school adolescents

\begin{tabular}{|c|c|c|c|c|c|c|}
\hline \multirow[t]{2}{*}{ Variables } & \multicolumn{3}{|c|}{ Univariate analysis } & \multicolumn{3}{|c|}{ Multivariate analysis } \\
\hline & Crude $\beta$ & $95 \% \mathrm{Cl}$ & $P$-value & Adjusted $\beta^{a}$ & $95 \% \mathrm{Cl}$ & $P$-value \\
\hline Mother's BMI & 0.082 & $0.06,0.104$ & $<0.001$ & 0.069 & $0.038,0.1$ & $<0.001$ \\
\hline Father's BMI & 0.082 & $0.059,0.106$ & $<0.001$ & 0.073 & $0.044,0.102$ & $<0.001$ \\
\hline Birth weight & 0.445 & $0.271,0.618$ & $<0.001$ & 0.357 & $0.123,0.59$ & 0.003 \\
\hline Household size & -0.057 & $-0.099,-0.015$ & 0.007 & -0.085 & $-0.158,-0.012$ & 0.022 \\
\hline Dairy products intake & 0.139 & $0.035,0.242$ & 0.009 & 0.194 & $0.013,0.375$ & 0.036 \\
\hline
\end{tabular}

${ }^{a}$ Adjusted regression coefficient; Forward MLR applied. Model assumptions are fulfilled. There were no interactions amongst independent variables. No multicolinearity detected. Coefficient of determination $\left(R^{2}\right)=0.131$; Final model equation $\left[Y=\beta_{0}+\beta_{1}\left(X_{1}\right)+\beta_{2}\left(X_{2}\right)+\beta_{3}\left(X_{3}\right) \ldots \ldots+\beta_{i}\left(X_{i}\right)\right]$

BMI $z$ - score $=-4.125+0.073$ (father's BMI) +0.069 (mother's BMI) +0.357 (Birth weight) -0.085 (household number) +0.194 (dairy products intake) 
0.38, $P=0.036)$. In contrast, there was a negative linear relationship between household size and BMI z-score whereby, one extra household member will contribute to a lower BMI z-score by 0.09 unit (adjusted $\beta=-0.09,95 \%$ $\mathrm{CI}=-0.16,-0.01, P=0.022$ ). Overall, $13.1 \%$ of the variation in BMI z-score in this sample was explained by the mother's BMI, father's BMI, birth weight, household size, and intake of milk and dairy products $\left(R^{2}=0.131\right)$ [24].

\section{Discussion}

The number of adolescents with overweight and obesity problem is skyrocketing globally over the last two decades. This study found $15.2 \%$ and $17.4 \%$ of the school adolescents in Terengganu (Malaysia) were overweight and obese, respectively. The proportions obtained by gender were comparable with national and worldwide data. Parental BMI, birth weight and intake of dairy products were positively associated with increases in BMI z-score. Effective preventive strategies have to be enforced to reduce the number of children/ adolescents with overweight and obesity problems.

This public health problem has been found to be associated with several determinants. Independent of other factors, positive linear associations were found between BMI z-score and parents' BMI, birth weight and intake of milk and dairy products whilst negatively associated with household size in this survey. In agreement with previous studies [25], parental weight status can have a significant influence on the body weight status of their offspring. While genetic predisposition has its contribution [26], the prominent influence lies in the obesogenic environment created by the parents within the household [27]. As the first social contact of the children, the parents are accountable in moulding their lifestyle particularly their dietary intake and physical activity patterns [28-30]. Parents who struggle with their body weight issues often face difficulties in establishing a healthy lifestyle within the household. Correspondingly, a local study has also found a direct relationship in dietary pattern between parents and child, particularly within the mother-child dyad [31]. There is evidence suggesting that the way parents shape their children's lifestyle may also depend on how they perceive their child's body weight status and this perception may be influenced by the background and socioeconomic status of the parents [32, 33]. Therefore, targeting the whole family in obesity interventions, especially among parents, may be more effective in reducing adolescence obesity. A meta-analysis by Berge \& Everts (2015) has found that family-based interventions targeting childhood obesity can successfully promote weight loss in the short and long-term [34].

The link between birth weight and childhood and adolescence obesity is clearly established. The connection between excessive birth weight and increased odds of obesity among children and adolescents has been reported in different populations across the world [3538]. While there is a potential of genotype and intrauterine growth factor, the positive linear relationship between birth weight and childhood/ adolescence obesity may also be attributed to maternal characteristics and subsequent environmental factors including physical activity and dietary intake [39]. This is again related to parental role although further longitudinal studies are required to confirm this relationship. Nevertheless, it is advisable to promote healthy lifestyle during pregnancy to avoid excessive gestational weight gain that can cause high birth weight of the offspring.

The findings from the present study have strengthened the available evidence on the inverse relationship between household size and obesity risk among adolescents [40, 41]. Smaller household size has been associated with higher socioeconomic status which leads to higher purchasing capacity and food affordability [41, 42]. In addition, parents of a smaller family size may contribute to different behaviours such as overfeeding and overprotection of their child's activity which has been linked with a higher obesity risk compared to parents from a larger family. Children with more siblings may also have less sedentary lifestyle or activities such as screen time which can be protective of childhood obesity.

Interestingly, a positive linear association was also found between consumption of milk and dairy product and obesity among adolescents. This finding was in agreement with previous studies which linked adiposity and dairy intake among early and mid-childhood [43, 44]. However, it was in contrast with other studies which reported the protective effect of dairy products against obesity $[45,46]$. Total dairy intake has been found to be positively associated with height and weight of overall participants and was positively associated with weightto-height ratio, fat mass, and fat-free mass among American boys [44]. The potential protective effect of dairy product on obesity in the current study may be confounded by the energy contribution of dairy products towards overall body weight status.

This study adds to the limited available evidence on obesity determinants among adolescents particularly in Terengganu, Malaysia. Very limited data have been published from this sub-urban state especially regarding adolescence obesity. Also, this study consistently shows the role of family and home environment factor that shapes the lifestyle of adolescents which eventually determines their health status. This study, however, failed to demonstrate any association between energy and macronutrients intake and physical activity level, and body weight status as reported previously [47]. This could be related 
to the methodological bias from the use of self-reported FFQ and cPAQ among this population. Nevertheless, FFQ and cPAQ are valid and reliable dietary assessments among children whilst appropriate measures such as trainings and assessment of underreporting had been undertaken to reduce the risk of bias $[48,49]$. The use of an objective assisted method for dietary intake and physical activity measurements may be useful to ensure more accurate findings among children and adolescents however would require large funding for a population study. A broad longitudinal prospective study starting from preconception is highly recommended to confirm the actual determinants of childhood and adolescence obesity. Another limitation of this study is the small proportions of children who responded to the survey, which has limited the generalisability of our results. The high percentage of invalid data had further restricted the sample size. This, partly, contributed by the differences in educational background and understanding among the respondents leading to common mistakes and refusal to participate. Additionally, the present cross-sectional analysis cannot establish any causal links between the observed predictors of obesity. Nevertheless, the findings were based on a specific population and need to be interpreted with vigilant especially in term generalisability to other population.

\section{Conclusion}

Positive linear relationships were found between body weight status of school adolescents and parental body weight status, birth weight and intake of milk and dairy products whilst a negative association was found with household size. This finding suggests that the obesity problem among adolescents in most population in the world may be largely attributed to family or home environment factor, although this interpretation may have to be made with discretion. Nevertheless, any promotion and intervention efforts to tackle obesity among children and adolescents should exclusively involve the parents at the earliest stages of childhood. Parental awareness, attitude and practice are crucial in the initial steps to promote healthy behaviours among the household to prevent adolescence obesity. Further research on a holistic interventional framework involving the role of individuals, family, community, and government is required by targeting the aforementioned significant determinants to prevent obesity among adolescents and more objective measurements and secondary data source should be considered to increase the reliability.
Health of Adolescents in Terengganu study; kg: Kilograms; m2: Metre squared; MOE: Ministry of Education; SEGAK: National Fitness Standard; MANS: Malaysia Adult Nutrition Study; NHMS: National Health Morbidity Survey; PE: Physical/ health education; SD: Standard deviation; SPSS: Statistical Package for the Social Sciences; JPNT: Terengganu State Education Department; UHREC: Universiti Sultan Zainal Abidin Human Research Ethics Committee; WHO: World Health Organization.

\section{Acknowledgements}

We would like to extend the gratitude to the Malaysian Ministry of Education, the Terengganu State Education Department for the permission to conduct this survey. Enormous appreciation to the PE teachers, parents and school adolescents for participating in this study. Special thanks to members of Health of Adolescents (HATs) study, collaborators and also enumerators for their valuable contribution to this study.

\section{Authors' contributions}

AA was the grant leader, who designed and conducted the study. NZ collected and analysed data. MRS conducted study and reviewed analysis. SWW designed and conducted the study. RMA conducted study and reviewed analysis. CP analysed and reviewed data. AA designed, reviewed analysis and directed the study. All authors were involved in writing and reviewing the paper and had final approval of the submitted and published versions.

\section{Funding}

This study was funded by the Malaysian Ministry of Higher Education (FRGS/2/2013/SKK/UNISZA/01/1).

\section{Availability of data and materials}

The datasets generated and/or analysed during the current study are not publicly available due research data are confidential and belongs to the Malaysian Ministry of Education but are available from the corresponding author on reasonable request.

\section{Declarations}

\section{Ethics approval and consent to participate}

Ethical approval was obtained from the Universiti Sultan Zainal Abidin Human Research Ethics Committee (UHREC) (Reference: UniSZA.N/1/628-1 Jld.2(11). Permission to conduct the study was obtained from the Malaysian Ministry of Education and Terengganu State Education Department. Parental informed consent for students' participation was obtained prior to the measurement. All methods performed in studies involving students' participation were in accordance with the ethical standards of the institutional research committee and with the 1964 Helsinki declaration.

\section{Consent for publication}

Not applicable.

\section{Competing interests}

The authors declare that they have no competing interests.

\section{Author details}

${ }^{1}$ Faculty of Health Sciences, Universiti Sultan Zainal Abidin, 21300 Kuala Nerus, Terengganu, Malaysia. ${ }^{2}$ Nuffield Department of Primary Care Health Sciences, University of Oxford, Radcliffe Primary Care Building, Radcliffe Observatory Quarter, Woodstock Rd, Oxford OX2 6GG, UK. ${ }^{3}$ Centre for Healthy Ageing and Wellness (HCARE), Faculty of Health Sciences, Universiti Kebangsaan Malaysia, Jalan Raja Muda Abdul Aziz, 50300 Kuala Lumpur, Malaysia. ${ }^{4}$ Faculty of Medicine, Universiti Sultan Zainal Abidin, 20400 Kuala Terengganu, Terengganu, Malaysia. ${ }^{5}$ Institute of Engineering Mathematics, Pauh Putra Campus, Universiti Malaysia Perlis, 02600 Arau, Perlis, Malaysia.

Received: 28 April 2021 Accepted: 25 Auqust 2021 Published online: 23 September 2021 


\section{References}

1. Nishtar S, Gluckman P, Armstrong T. Ending childhood obesity: A time for action. Lancet. 2016;387:825-7.

2. UNICEF, WHO, The World Bank Group Joint Child Malnutrition Estimates. Levels and Trends in Child Malnutrition. New York; 2016.

3. WHO. Obesity and overweight. 2020. https://www.who.int/news-room/ fact-sheets/detail/obesity-and-overweight. Accessed 19 Jan 2021.

4. Mirnalini K, Zalilah MS, Safiah MY, Tahir A, Siti HMD, Siti RD, et al. Energy and nutrient intakes: Findings from the Malaysian Adult Nutrition Survey (MANS). Malays J Nutr. 2008;14:1-24.

5. Yang W, Burrows T, MacDonald-Wicks L, Williams L, Collins C, Chee W, et al. Body Weight Status and Dietary Intakes of Urban Malay Primary School Children: Evidence from the Family Diet Study. Children. 2017;4:5.

6. Institute of Public Health (IPH) 2015. National Health and Morbidity Survey 2015 (NHMS 2015). Vol. Il: Non-Communicable Diseases, Risk Factors \& Other Health Problems. Kuala Lumpur; 2015.

7. Institute of Public Health (IPH) 2011. National Health and Morbidity Survey 2011 (NHMS 2011). Vol.2: Non-Communicable Diseases. Kuala Lumpur; 2011.

8. Institute of Public Health (IPH). The Third National Health and Morbidity Survey (NHMS III) 2006, Nutritional Status. Kuala Lumpur; 2008.

9. Institute for Public Health (IPH), National Institutes of Health, Ministry of Health Malaysia. National Health and Morbidity Survey (NHMS) 2019: Vol. I: NCDs - Non-Communicable Diseases: Risk Factors and other Health Problems. Kuala Lumpur; 2019.

10. Aryati A, Nurzaime Z, Nor Saidah AM, Shahril MR, Wafa SW, Amin RM, et al. Body weight status of school adolescents in Terengganu, Malaysia: a population baseline study. BMC Public Health. 2017;17:1-12.

11. Castro Ana Valeria B, Kolka CM, Kim SP, RNB. Obesity, insulin resistance and comorbidities - Mechanisms of association. Outl Genet Epidemiol. 2015:58:89-104.

12. Dietz W, Santos-Burgoa C. Obesity and its Implications for COVID-19 Mortality. Obesity. 2020;28:1005

13. Raychaudhuri M, Sanyal D. Childhood obesity: Determinants, evaluation, and prevention. Indian J Endocrinol Metab. 2012;16(Suppl 2):S192-4.

14. Sahoo K, Sahoo B, Choudhury AK, Sofi NY, Kumar R, Bhadoria AS. Childhood obesity: causes and consequences. J Fam Med Prim Care. 2015;4:187.

15. Birbilis M, Moschonis $G$, Mougios V, Manios Y. Obesity in adolescence is associated with perinatal risk factors, parental BMI and sociodemographic characteristics. Eur J Clin Nutr. 2013;67:115-21.

16. Ellulu M, Abed Y, Rahmat A, Ranneh Y, Ali F. Epidemiology of obesity in developing countries: challenges and prevention. Glob Epidemic Obes. 2014;2:2.

17. Gupta N, Goel K, Shah P, Misra A. Childhood Obesity in Developing Countries: Epidemiology, Determinants, and Prevention. Endocr Rev. 2012;33:48-70. https://doi.org/10.1210/er.2010-0028.

18. Crocker P, Bailey D, Faulkner R, Kowalski K, McGrath R. Measuring general levels of physical activity: preliminary evidence for the Physical Activity Questionnaire for Older Children. Med Sci Sports Exerc. 1997;29:1344-9.

19. Catherine CCW. Assessment of habitual physical activity and sedentary of obese children in Kuala Terengganu: Universiti Sultan Zainal Abidin; 2013.

20. World Health Organization (WHO). Obesity: preventing and managing the global epidemic. Report of a WHO consultation. World Health Organ Tech Rep Ser. 2000;894:i-xii 1-253.

21. Fadzli SA, Nor Saidah AM, AA, Wafa SW, Shahril MR, Nurzaim EZ, et al. HEMS : Automated Online System for SEGAK Analysis and Reporting. Int J Softw Eng Its Appl. 2016;10:89-104.

22. Nurzaime Z, Aryati A, Shahril MR, Fadzli SA, Ahmed A. Reliability of Anthropometric Measurements Conducted in National Physical Fitness Standard (SEGAK) Assessments among 12 Years Old School Adolescents in Terengganu, Malaysia. Malaysian J Public Heal Med. 2019;19:141-8.

23. WHO. WHO. Growth reference data for 5-19 years. 2007. https://www. who.int/toolkits/growth-reference-data-for-5to19-years/application-tools. Accessed 19 Jan 2017.

24. Aryati A, Zulaily N, Shahril MR, Abdul Manan NS, Fadzli SA, Wafa SW, et al. Obesity determinants among Malaysian schoolchildren: What is new? In: Proceedings of the Nutrition Society; 2017. p. E213.

25. Jane W, Susan C, Claire H, Robert P. Evidence for a strong genetic influence on childhood adiposity despite the force of the obesogenic environment. Hum Hered. 2008:87:398-404.
26. Nielsen LA, Nielsen TRH, Holm J-C. The Impact of Familial Predisposition to Obesity and Cardiovascular Disease on Childhood Obesity. Obes Facts. 2015:8:319-28.

27. Corsica JA, Hood MM. Eating disorders in an obesogenic environment. J Am Diet Assoc. 2011;111:996-1000. https://doi.org/10.1016/j.jada.2011. 04.011.

28. Robinson LN, Rollo ME, Watson J, Burrows TL, Collins CE. Relationships between dietary intakes of children and their parents: A cross-sectional, secondary analysis of families participating in the Family Diet Quality Study. J Hum Nutr Diet. 2015;28:443-51.

29. Fuemmeler BF, Anderson CB, Mâsse LC. Parent-child relationship of directly measured physical activity. Int J Behav Nutr Phys Act. 2011;8:17. https://doi.org/10.1186/1479-5868-8-17.

30. Scaglioni S, Salvioni M, Galimberti C. Influence of parental attitudes in the development of children eating behaviour. Br J Nutr. 2008;29(SUPPL.1):22-5.

31. Yang WY, Burrows T, Macdonald-Wicks L, Williams LT, Collins CE, Chee WSS. The Family Diet Study: A cross-sectional study into the associations between diet, food habits and body weight status in Malay families. J Hum Nutr Diet. 2016;29:1-8.

32. Chen H-Y, Lemon SC, Pagoto SL, Barton BA, Lapane KL, Goldberg RJ. Personal and parental weight misperception and self-reported attempted weight loss in US children and adolescents, National Health and Nutrition Examination Survey, 2007-2008 and 2009-2010. Prev Chronic Dis. 2014;11:E132

33. Zulaily N, Ahmad A, Shahril MR, Ahmed A. Parental perception of child's body weight status and its association with socio-demographicfactors among Malay children in primary schools in Kuala Terengganu. Malaysia J Nutr. 2020;26:173-87.

34. Berge JM, Everts JC. Family-based interventions targeting childhood obesity: A meta-analysis. Child Obes. 2011:7:110-21.

35. Yuan Z-P, Yang M, Liang L, Fu J-F, Xiong F, Liu G-L, et al. Possible role of birth weight on general and central obesity in Chinese children and adolescents: a cross-sectional study. Ann Epidemiol. 2015;25:5-9.

36. Cnattingius S, Villamor E, Lagerros YT, Wikstrom A-K, Granath F. High birth weight and obesity - a vicious circle across generations. Int J Obes. 2012;36:1320-4.

37. Qiao Y, Ma J, Wang Y, Li W, Katzmarzyk PT, Chaput J-P, et al. Birth weight and childhood obesity: a 12-country study. Int J Obes Suppl. 2015;5:S74-9.

38. Rito Al, Buoncristiano M, Spinelli A, Salanave B, Kunešová M, Hejgaard T, et al. Association between characteristics at birth, breastfeeding and obesity in 22 countries: The WHO European childhood obesity surveillance initiative - COSI 2015/2017. Obes Facts. 2019;12:226-43.

39. Ren JC, Wu JQ, Ji M, Rong F, Li YY, Gao ES, et al. The effect of high birth weight on overweight and obesity in childhood and adolescence. A cohort study in China. Saudi Med J. 2013:34:623-31.

40. Gurzkowska B, Kułaga Z, Litwin M, Grajda A, Swiader A, Kułaga K, et al. The relationship between selected socioeconomic factors and basic anthropometric parameters of school-aged children and adolescents in Poland. Eur J Pediatr. 2014;173:45-52.

41. Ahmad A, Zulaily N, Shahril MR, Syed Abdullah EFH, Ahmed A. Association between socioeconomic status and obesity among 12-year-old Malaysian adolescents. PLoS One. 2018;13:1-11.

42. Herforth A, Ahmed S. The food environment, its effects on dietary consumption, and potential for measurement within agriculture-nutrition interventions. Food Secur. 2015:7:505-20.

43. Wiley AS. Dairy and milk consumption and child growth: Is BMI involved? An analysis of NHANES 1999-2004. Am J Hum Biol. 2010;22:517-25.

44. Nezami M, Segovia-siapco G, Beeson WL, Sabaté J. Associations between Consumption of Dairy Foods and Anthropometric Indicators of Health in Adolescents. Nutrients. 2016;8:427.

45. Lu L, Xun P, Wan Y, He K, Cai W. Long-term association between dairy consumption and risk of childhood obesity: a systematic review and meta-analysis of prospective cohort studies. Eur J Clin Nutr. 2016;70:1-10.

46. Marcos-Pasero H, Aguilar-Aguilar E, de la Iglesia R, Espinosa-Salinas I, Gómez-Patiño M, Colmenarejo G, et al. Association of calcium and dairy product consumption with childhood obesity and the presence of a Brain Derived Neurotropic Factor-Antisense (BDNF-AS) polymorphism. Clin Nutr. 2019;38:2616-22. 
47. Rennie $\mathrm{KL}$, Johnson $\mathrm{L}$, Jebb SA. Behavioural determinants of obesity. Best Pract Res Clin Endocrinol Metab. 2005;19(3):343-58.

48. Koletzko B, Girardet J, Klish W, Tabacco O. Obesity in Children and Adolescents Worldwide : Current Views and Future Directions - Working Group Report of the First World Congress of Pediatric Gastroenterology, Hepatology, and Nutrition. J Pediatr Gastroenterol Nutr. 2002:2002(35):S205-12
49. Nor Aini J, Poh BK, Chee WSS. Validity of a children's physical activity questionnaire (CPAQ) for the study of bone health. Pediatr Int. 2013:55:223-8.

\section{Publisher's Note}

Springer Nature remains neutral with regard to jurisdictional claims in published maps and institutional affiliations.
Ready to submit your research? Choose BMC and benefit from:

- fast, convenient online submission

- thorough peer review by experienced researchers in your field

- rapid publication on acceptance

- support for research data, including large and complex data types

- gold Open Access which fosters wider collaboration and increased citations

- maximum visibility for your research: over $100 \mathrm{M}$ website views per year

At BMC, research is always in progress.

Learn more biomedcentral.com/submissions 